\title{
ENTREVISTA COM GEORGE MARCUS
}

\section{Patrícia Kunrath Silva*}

\section{Universidade Federal do Rio Grande do Sul - Brasil}

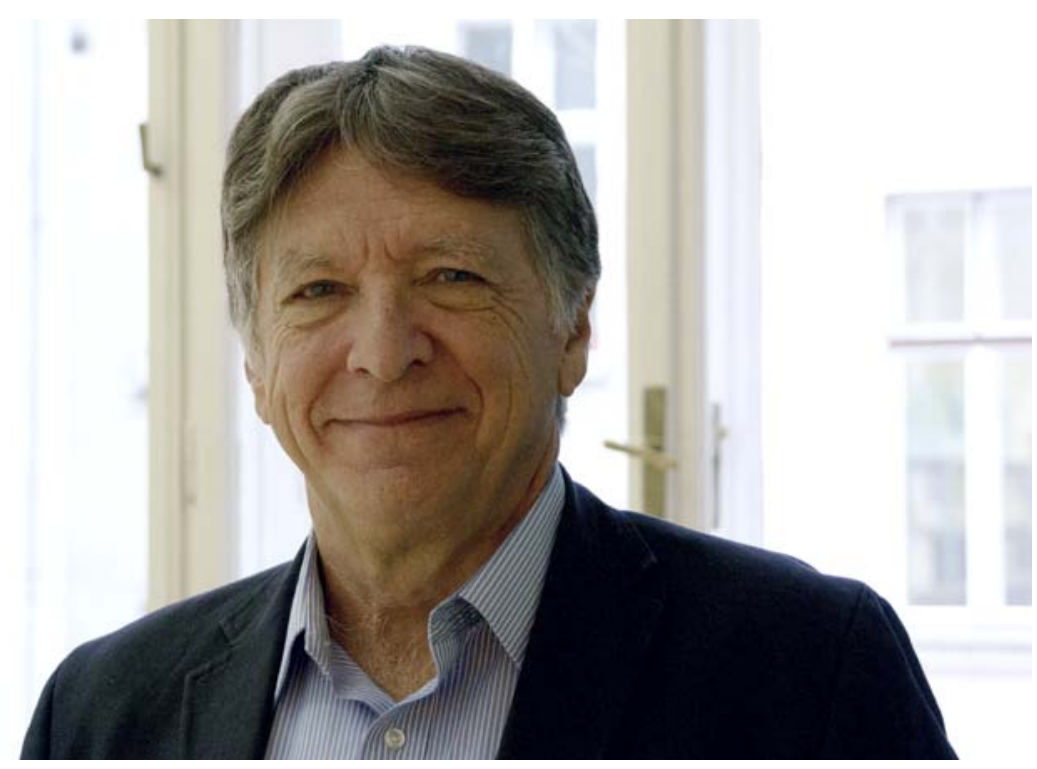

George Marcus.

* Doutoranda em Antropologia Social. Contato: patricia.kunrath@gmail.com

Horizontes Antropológicos, Porto Alegre, ano 23, n. 47, p. 401-416, jan./abr. 2017 http://dx.doi.org/10.1590/S0104-71832017000100014 
George Marcus, um dos mais destacados antropólogos estadunidenses, é atualmente o chefe do Departamento de Antropologia da Universidade da Califórnia em Irvine (UCI). Dentre suas numerosas publicações, ele é coeditor, com James Clifford, de Writing culture: the poetics and politics of ethnography (Clifford; Marcus, 1986) e coautor, com Michael J. Fischer, de Anthropology as cultural critique: an experimental moment in the human sciences (Marcus; Fischer, 1986). Marcus completou seu bacharelado (B.A.) em Política e Economia pela Universidade de Yale em 1968, estudou Antropologia Social pelo Queen's College, Cambridge em 1968-69 e concluiu seu doutorado $(\mathrm{PhD})$ em Antropologia pela Universidade de Harvard em 1976 com um estudo focado nas elites em Tonga. Foi professor e chefe do Departamento de Antropologia na Universidade de Rice, Texas, de 1980 a 2005, da qual recebeu o título de Professor Emérito.

Fundou a revista Cultural Anthropology da Society for Cultural Anthropology, entidade que integra a American Anthropological Association (AAA) e foi editor da coleção Late Editions: Cultural Studies for the End of the Century. George Marcus dedica sua carreira a (re)pensar os paradigmas da produção antropológica e da escrita etnográfica, partindo de perspectivas da escrita literária e desenvolvendo o conceito de etnografia multissituada. Especializou-se também no estudo de elites econômicas, políticas e intelectuais, tendo publicado ao lado de Peter Dobkin Hall o livro Lives in trust: the fortunes of dynastic families in late twentieth-century in America (Marcus; Hall, 1992). O aspecto colaborativo de sua obra marca a centralidade da questão para o antropólogo, que vem trabalhando ao lado de pensadores como Paul Rabinow, artistas e designers.

Nesta entrevista concedida a Horizontes Antropológicos, em 21 de dezembro de 2015, na Universidade da Califórnia em Irvine, ele discute, entre outros temas, a história da antropologia, sua trajetória e produção intelectual.

\section{Entrevista}

Patrícia Kunrath Silva: Você poderia nos falar de sua trajetória profissional, incluindo seu extenso trabalho de campo em Tonga e como você desenvolveu o interesse em (re)pensar etnografia(s)? 
George Marcus: Minha apresentação inicial [à antropologia] foi por meio de minha irmã, que casou com um antropólogo. Ambos foram fazer o trabalho de campo inicial dele entre os semai na Malásia e a minha apresentação mais forte à antropologia eram cartas que ela enviava de lá durante o ano de pesquisa. Isso me apresentou ao trabalho de campo, por meio da família, quando eu estava no segundo grau e eu senti que era realmente algo que eu gostaria de fazer, uma aventura que eu gostaria de ter. Então, eu entrei na antropologia atraído pelo método de investigação, pela experiência e trabalho de campo como uma forma de conhecer coisas e encontrar mundos. Eu cresci em uma cidade pequena e a antropologia permitia aprender sobre outras formas de vida a partir de seus interiores. Eu estudei em uma universidade de elite durante a graduação - Yale - e comecei a fazer disciplinas de antropologia, mas eu as achei, para ser honesto, bastante chatas. Eu me encontrei em uma formação que combinava ciência política e economia, mas que envolvia trabalho intensivo com um grupo pequeno de professores e alunos. Meus colegas eram, em sua maioria, pessoas que seguiram carreiras na diplomacia, direito, desenvolvimento, mas definitivamente não na antropologia. Eu era o único aspirante a antropólogo em um programa formal das ciências sociais que levava a prestigiosas carreiras de pesquisa ou de negócios. Então, durante a graduação, eu era o antropólogo em meio à alteridade, mas não o comum "outro" do interesse antropológico. Eu gostava dessas outras formas de pensamentos e culturas acadêmicas, e eu gostava de me sentir como exceção. Essa obliquidade no campo ao qual me dediquei me definiu de alguma forma. Quando eu eventualmente recebi treinamento em antropologia e desenvolvi uma carreira na disciplina, me senti imerso nela intelectualmente, mas nunca me integrei completamente à sua ideologia. Parcialmente, isso tem a ver com o estado de desenvolvimento da antropologia enquanto disciplina, ao menos nos Estados Unidos. Eu cheguei em uma série de instituições (no final dos anos 1960, início dos anos 1970 - Yale, Cambridge, Harvard - talvez tivesse sido diferente se eu tivesse ido para Chicago!) nas quais os paradigmas específicos de pesquisa da antropologia, que foram uma vez famosos, naquele período já estavam exauridos e em declínio. Após me formar em Yale, fui para Cambridge por um ano e pensadores como Leach, Fortes e Goody estavam lá, mas seus ensinamentos tornaram-se maçantes. Então eu fui para Harvard e o paradigma outrora excepcional (relações sociais e a assinatura de projetos colaborativos no México, Brasil, em alguns países da África e Indonésia, que 
produziram Clifford Geertz e outros mais cedo) estava em declínio. Então eu nunca abracei a disciplina. Eu a aprendi, transitei no seu meio, me fascinei por ela intelectualmente. De alguma forma acho que eu seria um bom historiador da antropologia se eu não a tivesse "praticado". Ela tem sido mais um objeto de interesse para mim do que a incorporação [embodiment] de uma profissão, ou talvez seja um pouco de ambas as coisas. Eu ocupei uma posição liminar, eu acho. Talvez muitas antropólogas e antropólogos se sintam assim.

Em Harvard, a pesquisa era organizada em termos de projetos coletivos de longo prazo, o que é bastante incomum para a antropologia. Quando eu cheguei em Harvard, alguns estudantes, que não queriam se juntar aos projetos coletivos, precisaram achar seus próprios projetos, o que muitos fizeram muito bem. Eu tinha que achar um lugar para mim em Harvard e não sabia aonde ir. Havia uma vaga em um projeto coletivo sobre gerenciamento de disputas e antropologia do direito no Pacífico (a maior parte da pesquisa era feita em Fiji). Eu me juntei a esse projeto e escrevi minha tese sobre o reino de Tonga, onde eu estudei um sistema reformado, mas ainda bastante feudal de chefia. Assim, o início da minha carreira seguiu um caminho de especialização em estudos de áreas e naquele período, início dos anos 1970 até o meio dos anos 1980, pesquisas na Oceania (Melanésia, Polinésia, Micronésia) eram muito importante para certas tendências teóricas na antropologia estadunidense (como por exemplo a história estruturalista na Polinésia; antropologia psicológica, gênero, teorias do self na Melanésia e Nova Guiné). Esse foi o período pré Writing culture, e grupos de jovens antropólogas e antropólogos de Chicago, Columbia e novos departamentos da Califórnia estavam fazendo trabalhos teóricos muito interessantes em seus primeiros projetos em uma tradição estabelecida em sociedades oceânicas que estava no centro do desenvolvimento da antropologia enquanto disciplina. Foram então um momento e um lugar muito interessantes para ser um iniciante da antropologia. Os estudos da Polinésia eram dominados pelo trabalho de Marshall Sahlins em história estruturalista, mas para bem ou para mal eu não fiz nada disso.

Eu fui para Tonga. Eu fiz o meu projeto em resolução de conflitos, o que me levou ao centro da política das elites. A maior parte das pessoas no meu projeto, os estudantes que entraram no projeto sob a supervisão de um jovem antropólogo que não ficou em Harvard por muito tempo (Karl Friederich-Koch, que faleceu precocemente no Cairo, e que havia sido treinado em Berkeley, na linhagem de Laura Nader e seus esforços para promover a antropologia 
do direito) tinham passado por escolas de direito e trabalhado em Fiji. Eu fui o único no grupo a ir a Tonga. Eu estava ocupado com o meu material de dois anos de pesquisa de campo em Tonga e escrevi sobre tópicos acerca da política até o início dos anos 1980. Eu não trabalhei mais em Tonga desde os anos 1970, mas mantive um interesse na história e eventos contemporâneos dessa sociedade. Ela fez eu me tornar parte de um subclã muito pequeno de antropólogos!

Patrícia Kunrath Silva: Quem você diria que foram as maiores influências no seu trabalho? Em termos teóricos, quais trabalhos clássicos ou contemporâneos mais influenciaram o seu pensamento e por quê?

George Marcus: Isso foi mudando com o tempo, mas eu preciso dizer que o primeiro trabalho que realmente me surpreendeu, ficou comigo e sobre o qual eu acabei escrevendo um artigo para uma revista de teoria literária, Representations, que me levou às questões da narrativa etnográfica, foi Naven de Gregory Bateson. Ele tinha esse olhar profundo da experiência antropológica que eu admirava. Ele veio de uma linhagem aristocrática de acadêmicos, e ele mostrou confiança e uma originalidade destemida. Houve outro trabalho que me influenciou muito, mesmo antes de Naven. Meu cunhado que me apresentou à antropologia também me apresentou a Marcel Mauss e à ideia da dádiva. Eu não tinha uma cópia do livro de Mauss para ler. É claro que isso é bem apropriado, pois Mauss tem sido uma doutrina central, construída sobre uma ideia poderosamente simples, que tem unificado muito do pensamento antropológico, tanto sofisticada quanto ideológica. Meu cunhado me contou sobre Mauss como uma espécie de doutrina central, acerca da qual significativas teorias antropológicas ainda são construídas. Eu fiquei muito impressionado com o poder da ideia da dádiva, de sua economia intelectual. Então o meu folclore pessoal do campo tem sido moldado pela descoberta de Naven quando eu estava em Cambridge no final dos anos 1960 e pela história da dádiva como uma espécie de tradição oral.

Quando eu consegui meu primeiro emprego como professor na Rice University em Houston, Texas, depois de Harvard e de ter ido a Tonga, eu colaborei com um novo colega chamado Dick Cushman. Nós demos um curso, um seminário sobre etnografias clássicas e devo dizer que para mim aquele curso, dado o pano de fundo que expliquei a você, foi uma forma fantástica 
de me aproximar daquilo que me atraía na antropologia, olhando para suas produções, suas obras de conhecimento, enquanto um gênero literário, na narrativa e na qualidade retórica da etnografia. A produção de conhecimento enquanto obra de uma narrativa era uma ideia sedutora. A escrita se tornou o meio da minha reeducação em antropologia após ter passado por departamentos famosos, mas não inspiradores.

Durante meu tempo em Harvard, uma das pessoas mais interessantes que eu conheci foi James Clifford, na época estudante pós-graduando em História. Ele estava pesquisando a história da etnografia francesa e escreveu seu primeiro livro sobre o antropólogo-etnógrafo francês na Nova Caledônia, Maurice Leenhardt (cuja obra clássica Do kamo fora um dos textos com os quais se entendia a reflexividade na escrita etnográfica). Em Harvard, passavam inúmeros antropólogos franceses e Clifford fazia as perguntas mais interessantes. Eu o conhecia como uma figura que se destacava no grupo e, mais tarde, quando eu já havia me mudado para Rice, comecei a notar os artigos de Clifford aparecendo em várias revistas de língua inglesa que estavam conectando o trabalho de campo à escrita etnográfica. Isso era algo bastante incomum de se fazer na época. Havia alguns outros antropólogos que estão em Writing culture que estavam fazendo isso como, por exemplo, Vincent Crapanzano e Renato Rosaldo. Quando eu ensinei etnografia em Rice, a questão desta enquanto narrativa se tornou um quadro [framework] para pensar minha própria posição na escrita sobre Tonga em um registro completamente diferente daquele que estava em voga na época, a história estruturalista. Eu estava escrevendo sobre Tonga em termo de elites. Talvez devido a meu lugar na política e economia em Yale. Ao mesmo tempo, eu me interessei por como se descreviam certas regiões ou áreas em termos de narrativa. Então mais uma vez, seguir uma linha menor ou marginal na minha área de interesse antropológico me levou a novos quadros para pensar. Eu me tornei muito atento à escrita etnográfica e comecei a pensar sobre a escrita de Marshall Sahlins, não em termos de sua linhagem e história, mas em termos de sua retórica.

O estruturalismo já era passé quando comecei a dar aulas em Rice, em 1975. Havia pessoas que faziam trabalhos estruturalistas, o estruturalismo era bem respeitado, mas não era mais o paradigma vigente. De qualquer forma, a tradição norte-americana em antropologia sempre foi bastante eclética, talvez até mesmo caótica, com muitos fios condutores distintos. Geertz estava emergindo, especialmente em sua influência transdisciplinar e ele era muito 
agradável por seu brilhantismo acessível enquanto escritor. Posso contar também uma outra história: todas as teorias pós-estruturalistas francesas que se tornaram muito importantes nos anos 1980 estavam sendo lidas por pessoas que tinham acesso a elas de segunda mão, as traduções não eram muito benfeitas. Quando eu estava na pós-graduação, Foucault estava sendo muito lido, muito Habermas, não se lia muito Derrida e poucas pessoas conheciam Barthes. A escrita feminista não era muito popular entre os homens. A escrita feminista não era poderosa, centralmente poderosa, como se tornou. Então eu não tinha muito conhecimento teórico, exceto pelo completo interesse na produtividade do pensamento e no olhar das etnografias enquanto narrativas e o que isso significava para mim em meu próprio trabalho. A epifania teórica veio mais tarde para mim, do início dos anos 1980 em diante, em um arranjo maravilhoso de amizades transdisciplinares. Um surfista solitário, eu acabei pegando uma onda que se tornou importante para outros. Mais do que eu entendia.

Patrícia Kunrath Silva: Em seu livro Anthropology as cultural critique, a leitora e o leitor encontram já na introdução duas frentes que a antropologia no século XX prometera promover: um contradiscurso a narrativas ocidentais homogeneizantes, voltando-se para a diversidade; e o uso de "retratos de outros padrões culturais para fazer uma reflexão autocrítica de nossos próprios modos". Olhando para trás, como você percebe esse momento? Você considera que a antropologia tenha entregado o que prometera, promovendo essa autocrítica entre pensadoras e pensadores e suas próprias "culturas"?

George Marcus: A resposta para isso tudo é sim. Anthropology as cultural critique era uma função intrínseca e não desenvolvida da antropologia, ou pelo menos das antropologias no chamado Ocidente: antropologia estadunidense de uma certa forma, francesa de outra, mas eu conhecia basicamente a estadunidense. A figura icônica era Margaret Mead, apesar de ela ter tido uma carreira acadêmica bastante marginal - ela era uma grande intérprete pública da antropologia na cultura norte-americana. Nós queríamos algo diferente na época: uma onda de pesquisas críticas em antropologia estava apenas aguardando para ser desenvolvida após os turbulentos anos 1960 até os quietos 1980.

No meu primeiro (e de longa duração) emprego como professor eu tive muita sorte. $\mathrm{O}$ departamento no qual entrei em Rice não era um dos 
[departamentos] centrais. Foi fortuito estar nas margens de uma forma, mas em uma universidade privada de muita qualidade. Tínhamos um departamento pequeno de sete pessoas, com um programa fraco de pós-graduação. Em cinco anos, devido a aposentadorias e mudanças, o departamento estava reduzido a duas pessoas, Stephen Tyler e eu.

O reitor, com quem eu tinha um bom relacionamento, nos encarregou de reconstruir o programa. Nós formamos um novo departamento em um momento fortuito - o mercado de empregos estava muito favorável para a contratação de bons antropólogos, e a crítica intelectual estava crescendo baseada na linguagem e na crítica cultural (rotulada mais tarde de "pós-modernismo") à qual Stephen Tyler e eu éramos muito sensíveis. Trouxemos Mike Fischer de Harvard, Julie Taylor da Universidade da Califórnia e um número de antropólogos jovens muito interessantes. Começamos a atrair estudantes de pós-graduação orientados especificamente para o que tínhamos a oferecer enquanto grupo. O departamento ficou devotado a duas preocupações que se entrecruzavam e nos guiavam: "a antropologia enquanto crítica cultural" e "a escrita (a dificuldade da representação) é importante”. De meados dos anos 1980 até os anos 1990, nós tivemos uma grande reputação com essa especialização. Quando eu saí em 2005 para vir para a Califórnia, nós éramos dez docentes e admitíamos quatro novos discentes de pós-graduação por ano, ainda um departamento muito pequeno, em uma universidade muito rica e respeitada de altos padrões, mas no Texas. Nós atraímos estudantes "alternativos" que queriam se engajar com essa tendência intelectual. Nós os tratávamos como colegas "juniores" desde o início e esperávamos deles projetos criativos e críticos. Como tudo, funcionava para alguns, mas não para outros. Da média de 70 estudantes que tivemos durante aqueles anos, a maioria dos quais seguiram interessantes carreiras acadêmicas, a abordagem de Rice à antropologia se manteve como uma fonte de compromisso até os dias de hoje. De minha parte, aprendi a antropologia que sei (e com a qual estou comprometido) nesse emprego em Rice, tentando formatar um programa com as pessoas que se juntaram a nós. Não foi na pós-graduação nem na graduação, como eu expliquei, mas em meu primeiro emprego e da melhor forma possível, com meus colegas, professores a alunos.

O livro Anthropology as cultural critique foi majoritariamente uma colaboração entre Mike Fischer e eu. Ele tem um legado europeu muito forte, com sua família em Viena (os pais refugiados durante a Segunda Guerra). Ele foi treinado em Chicago e tinha sido professor assistente em Harvard antes

Horizontes Antropológicos, Porto Alegre, ano 23, n. 47, p. 401-416, jan./abr. 2017 
de Rice (ele está no MIT [Instituto de Tecnologia de Massachusetts] desde 1992 e foi um dos principais nomes a desenvolver os estudos da ciência, que se tornaram, eu diria, a tendência dominante para pensamentos inovadores em antropologia desde o período de Writing culture). Ele também estava no volume de Writing culture, mas ele tinha reservas quanto à profundidade e às implicações daquela crítica advinda de estudos literários para a antropologia. A crítica principal na antropologia para antropólogos foi Anthropology as cultural critique e esse foi um trabalho colaborativo. Essa crítica absorveu a lição de Writing culture, mas baseou-se mais na aplicação de vários movimentos na teoria social do século XX em relação ao estilo etnográfico de pesquisa em antropologia. De qualquer forma, toda a minha carreira desde Rice até o presente momento tem sido definida por colaborações de diversas formas, mesmo sendo o modelo-padrão da antropologia sermos o solitário entre a alteridade - se "apropriar" de uma parte do trabalho de campo e desenvolvê-lo para a coletividade. Eu sempre me interessei mais em construir a mesa, por assim dizer, do que trazer algo para ela com a minha marca em cima. Eu tenho essa identidade convencional de alguém que trabalhou em Tonga, pesquisou elites, mas a real transformação de métodos antropológicos está alinhada com colaborações que têm sido minha real paixão, dirigida por pensar como a mudança do que chamamos de condições sociais, globais e históricas emergentes criam novas oportunidades para pensar por meio de colaborações.

Patrícia Kunrath Silva: E você aborda colaborações não apenas entre pares, entre chamados intelectuais e acadêmicos, mas também com as pessoas com as quais pesquisa?

George Marcus: Sim, eu estou experimentando com isso agora, mas não em Tonga. A ideia é pensar modos de intervenção nas cenas clássicas de trabalho de campo, as quais as antropólogas e antropólogos, acostumados com relações muito exclusivas e íntimas com os sujeitos que eles observam por meio da participação - "estando lá" - achariam aceitáveis e esclarecedoras. É claro que há ONGs [organizações não governamentais] e ativistas por meio dos quais inúmeros projetos de trabalho de campo passam, mas eu tenho em mente um tipo mais específico de colaborações com designers e artistas cujos locais específicos de interesse se sobreponham com os do etnógrafo. Do ponto de vista da pesquisa etnográfica, em quais pontos da pesquisa e de 
quais formas as colaborações com distintos designers e artistas são produtivas e úteis? Como seriam tais colaborações? Quais suas normas? O que elas produzem? Essas são as questões que me interessam.

Desde 2011, e por meio do Centro de Etnografia que fundei na Universidade da Califórnia em Irvine quando cheguei em 2005, trabalhei em cinco projetos com dois designers cênicos (do teatro e um com formação também em antropologia). Cada um teve uma evolução e trajetórias distintas enquanto trabalho de campo. O pano de fundo intelectual para esse recente trabalho foi uma série de conversas que tive com Paul Rabinow, principalmente em meados dos anos 2000 e que publicamos como um livro de conversas intitulado Designs for an anthropology of the contemporary em 2008. Dentro do quadro de projetos de trabalho de campo, tentamos substituir essa forma hierárquica e extrativa, que sempre foi a "colaboração" dos antropólogos no trabalho de campo, por um processo de estúdio. Malinowski talvez ainda seja a imagem do antropólogo como um nativo marginal, mas as relações e situações do trabalho de campo atual requerem entendimentos mais complexos e produções de encontros e participações que o pensamento por meio de colaborações específicas requer. Formas de participação da alteridade em pesquisas fora do formato etnógrafo-informante requerem não apenas a produção de formas intermediárias entre arquivos privados de notas de campo e a publicação convencional, mas oficinas, estúdios, locais de performances, plataformas digitais e organizações sistemáticas na internet. Essas alternativas têm sido um dos principais interesses do Centro de Etnografia em Irvine: experimentar com formatos em um nível que conseguimos financiar - fazer oficinas, estúdios, "paralocais" adjacentes à pesquisa etnográfica em andamento - e oferecer um fórum de discussão de projetos mais ambiciosos e de larga escala que venham a surgir. O que tem sido notável para mim é a descoberta da quantidade de centros e atividades existentes em inúmeras universidades atualmente. A antropologia, entre outras disciplinas, na Universidade da Califórnia parece estar especialmente interessada nessas mudanças no modelo tradicional de pesquisa etnográfica. Por exemplo, existem centros experimentais em departamentos de antropologia nas Universidades da Califórnia Berkeley, Davis, San Diego e Riverside.

Patrícia Kunrath Silva: O que você acha da antropologia aplicada e do papel político da disciplina? 
George Marcus: A antropologia aplicada está viva e muito bem nos Estados Unidos. Ela partilha muito da tendência experimental que venho escrevendo com a maior parte da antropologia acadêmica. Seria bom para acadêmicos pensar realisticamente em treinar seus estudantes para carreiras fora do ensino universitário. Isso incluiria não apenas consultorias administrativas, mas uma série de causas ativistas, apoiadas por formas ambiciosas (e mesmo agressivas) pelo filantrocapitalismo. Eu acho que há muito potencial nisso. Os estudantes têm ideias e precisam vendê-las, colocá-las no mercado. Você poderia dizer que isso é muito cinismo, mas ainda em função do incrível sucesso do empreendedorismo tecnológico da informática, existem novos dogmas do trabalho intelectual, enfatizando criatividade e inovação - "pensar fora da caixa", como diz o clichê - que parecem atraentes à forma como antropólogos desenvolvem ideias às margens de disciplinas mais tradicionais. No entanto, essa fonte de inspiração é regida por normas clássica de competição do mundo dos negócios. Antropólogos que gostam de ter tempo, mesmo ao desenvolver suas melhores ideias, podem ser triturados pelas engrenagens de uma máquina darwiniana muito impaciente, para a qual as ideias são boas, mas o fracassar também o é frequentemente. A antropologia é um espaço mais devagar de pesquisa e desenvolvimento. Enquanto antropólogos aplicados e acadêmicos têm pontos em comum, os primeiros tendem a conformar a ponta da competição de negócios não tolerando o ruminar de ideias que parecem não estar funcionando ou mesmo mergulhar em abstrações teóricas. Divagar, alimentar abstrações, seguir ideias aonde quer que elas te levem é algo que antropólogos não aplicados gostam de fazer e isso mantém a barreira clássica entre a antropologia da universidade e a antropologia aplicada.

Patrícia Kunrath Silva: E como fica a questão da colaboração quando você está trabalhando com elites?

George Marcus: As políticas de se trabalhar com elites ou experts de diversos tipos estão presentes em inúmeros projetos etnográficos atuais. Para entrar ou definir o campo, você precisa de um patrocínio negociado. Essa política afeta o que você pode fazer enquanto pesquisador. Esse foi sempre o caso, mas existia um paradigma de apresentação dos alunos ao trabalho de campo, um paradigma imperial, no meu tempo. Podemos dizer que os estudos de elites na antropologia se originaram com a política da entrada de campo por 
meio da escuta de experts e elites e, se você quiser ir mais além, tornando-os seus sujeitos de pesquisa. No meu caso fiz isso repetidamente. Estudei chefes polinésios, nobres portugueses, famílias dinásticas norte-americanas e seus banqueiros e consultores financeiros, connoisseurs de artes, intelectuais interessados em ser consultores e comentaristas políticos e burocratas diplomatas. No entanto, se você perguntar se trabalhei em um campo bem constituído ou mesmo definido - da antropologia das elites - eu acho que não. Tal campo nunca se desenvolveu, ou pelo menos não desenvolveu muita coerência. Eu tentei explicar o porquê disso, em 1983 em uma coletânea que editei sobre antropologia das elites, quando eu tinha a ambição juvenil de construir um campo. A importância dos estudos da ciência, a partir dos anos 1990 (por meio dos quais os antropólogos passaram a circular nos mundos das elites médicas e das ciências naturais), e o fato de as políticas da pesquisa de campo envolverem relações substanciais com elites que definem os arranjos nos quais muitos trabalhos podem existir tornam a pesquisa das elites de fato uma dimensão integral de muitos projetos. Circunstancialmente, eu fui mais um antropólogo das elites do que um promotor de uma especialidade. Poucos estudiosos como Marc Abélès, que estuda as políticas de Estado, fizeram realmente uma antropologia das elites mais profunda e sistematizada.

Em 1969, Laura Nader publicou um artigo intulado "Up the anthropologist..." no livro seminal Reinventing anthropology. Desde então esse artigo tem sido muito influente quando qualquer antropólogo estadunidense fala sobre estudar as elites, sobre "estudar para cima" ("studying up"), mas os resultados e oportunidades emergem da criação de redes em assuntos sobre os quais você tem certas apostas - o estudo de raça, classe, doenças, dívidas, por exemplo. Então, dada a natureza do que constitui o trabalho de campo atualmente, eu diria que todo mundo está fazendo um pouco de antropologia das elites. Realmente depende das perguntas que o antropólogo pergunta ou nas quais está interessado. Existem certas áreas e tópicos, como a que nos interessa, por exemplo, da filantropia e seu caráter mutável, que entra diretamente nos usos e normas de deslocamento de concentrações de riqueza para benefício da humanidade. Esse é um tópico-chave que pode definir a antropologia das elites como um campo, mas o conhecimento antropológico nessa arena é bastante escasso e raramente conectado com o trabalho de campo sobre poderes em outros aspectos. Em geral, eu diria que o estudo das elites para os antropólogos encontra menos barreiras por problemas de acesso do que pelo desgosto moral ou ético pelo assunto. 
Patrícia Kunrath Silva: E como aparece a questão da antropologia estudando sua própria sociedade no caso norte-americano?

George Marcus: Bem, eu consigo pensar em uma série de antropólogos reconhecidos que fizeram suas carreiras estudando muitos tópicos nos Estados Unidos. Não é um local novo de estudo. Sempre esteve presente de forma poderosa. Ainda assim, ideologicamente, tem sido uma categoria um tanto invisível para os antropólogos, mesmo que haja uma sociedade para estudo na América do Norte com classes, raça, gênero, etc. Sempre houve estudos sobre o país, mas tem sido um programa de pesquisa pouco desenvolvido. Trabalhar nos Estados Unidos sobre os Estados Unidos sempre foi um desses tópicos um tanto impróprios. É um ritual dizer para novos alunos de pós-graduação não trabalharem em sua própria sociedade ou eles nunca conseguirão um emprego. Temos que lembrar que a antropologia é imperial: quem é alteridade? São indígenas, imigrantes..., não nós. Uma das grandes falências da antropologia, e há trabalho histórico escrito sobre isso, foi largar os estudos de raça e se tornar apenas o estudo da cultura, especialmente na sociedade norte-americana. Apagar o racismo na precoce antropologia norte-americana resultou em colocar os estudos de raça de lado por um bom tempo. Foi um erro em retrospectiva.

Patrícia Kunrath Silva: E quanto a seus trabalhos enquanto editor?

George Marcus: Dois grandes projetos editoriais foram a fundação da revista Cultural Anthropology em 1985, agora uma revista próspera e continuamente inovadora de antropologia, que fui chamado para fazer quando se estabelecera a Sociedade para Antropologia Cultural [Society for Cultural Anthropology] e a série Late Editions para a editora da Universidade de Chicago [University of Chicago Press]. Eu produzi os seis primeiros volumes de Cultural Anthropology, também refletindo as mudanças que aconteciam na antropologia na época, em direção a movimentos de teorias culturais críticas. Essa característica tem sido mantida como a sua imagem entre revistas oficiais da Associação Americana de Antropologia [AAA - American Anthropological Association]. O projeto Late Editions de livros anuais, marcou o fim do século na última década do século XX. Eu tinha um contrato com a editora da Universidade de Chicago e produzi um volume editado por ano de 1992 a 2000, 
em diversos tópicos. Durante os anos 1980 e 1990, o conceito de representação documentária foi desafiado de inúmeras maneiras, então como poderíamos representar as mudanças que aconteciam no fim do século? Favorecendo a importância de teorias dialógicas para repensar a prática e a narrativa etnográficas naquele momento enviávamos a cada ano antropólogos experientes de volta a seus locais de expertise para analisar as mudanças que estavam ocorrendo na virada do século nesses lugares. Cada um deveria produzir artigos baseados em entrevistas ou diálogos de seus locais ao invés de uma monografia com a voz da autoridade etnográfica. Os resultados foram muito variados e interessantes. Nós tínhamos reuniões anuais do "coletivo editorial" na Rice para avaliar os materiais recebidos ao longo do ano e planejar os projetos do próximo. Era como trabalho editorial de uma revista, exceto que as reuniões eram conduzidas por pessoas que eram também acadêmicas e assim se tornavam seminários interessantes sobre a forma etnográfica bem como sobre o trabalho editorial da série. Eu diria que o projeto anual da Late Editions teve um impacto duradouro nas pessoas que participaram desse processo editorial coletivo. Ele ensinava experimentação no quadro do método etnográfico e também definia um meio de trabalho colaborativo em antropologia que se tornou muito mais influente enquanto tema de interesse geral desde o início dos anos 2000. O trabalho da Late Editions foi feito no princípio da revolução da internet - essa condição foi abordada no terceiro volume da série, intitulado Connected. Hoje, sua forma pode ser vista como antiga - o encontro literal de um coletivo para produzir volumes que refletiam mudanças emergentes - mas a forma de antropólogos pensarem juntos projetos comuns nunca envelhece. Dois projetos que parecem ter saído a partir de Late Editions e suas redes são dois volumes publicados pela Cornell University Press: Fieldwork is not what it used to be: learning anthropology's method in a time of transition (2009), editado por James Faubion e eu, e Theory can be more than it used to be: learning anthropology's method in a time of transition (2015), editado por Dominic Boyer, James Faubion e eu. Ambos podem ser vistos como descendentes do tipo de projeto documental sem a ajuda da narrativa documental autoritária que foram as Late Editions nos anos 1990.

Patrícia Kunrath Silva: No que você está trabalhando no momento?

George Marcus: Eu estou trabalhando em um livro com Luke Cantarella e Christine Hegel, um designer cênico e uma antropóloga, anteriormente da 
Universidade da Califórnia em Irvine, mas que agora vivem no Brooklyn, Nova Iorque. No meu espírito de projetos para repensar a antropologia estamos produzindo esse livro baseado em cinco projetos onde colaboramos. Cada projeto mostra um tipo diferente de intervenção em pesquisas etnográficas em andamento feitas por antropólogos ou grupos de antropólogos. Desenhamos as intervenções como "segundos atos" após o trabalho de campo ser concluído ou como intervenções no curso ou como oficinas de projetos que ainda não foram bem concebidos ou acabados por alguma publicação profissional significativa. Estamos utilizando o título Encontros produtivos [Productive encounters]. A ideia é criar micropúblicos ou recepções granulares para o pensamento etnográfico que normalmente é exposto apenas em livros acadêmicos ou artigos. Nós estamos desenvolvendo meios para produzir formas intermediárias, por assim dizer, em projetos, com seus próprios resultados que irão de fato de se relacionar com formas mais tradicionais de gêneros acadêmicos mais cedo ou mais tarde.

Um projeto relacionado - também metodológico - é com Douglas Holmes, recentemente reconhecido por seu trabalho sobre o "desejo etnográfico" de bancos centrais (The economy of words, publicado pela University of Chicago Press) na medida em que essas poderosas instituições se tornam mais publicizadas e extremante políticas ao redor do globo. Trabalhando com elite e experts, temos um interesse de longa data em "alinhamentos" como uma chave central metodológica para antropólogos que geralmente têm acesso limitado. Mais recentemente, alguns dos escritos de Stanislavsky sobre como os atores preparam seus papeis têm nos interessado para pensar como os antropólogos se preparam para lidar com o acesso que tiverem junto a elites. "Alinhamento" é mais do que o acesso de um repórter, por exemplo; é o tipo de internalização de um papel que melhora os modos de comunicação na pesquisa etnográfica com elites, especialmente para aqueles que sentem mudanças sísmicas de suas próprias práticas e relações com públicos, sociedades, etc.

Finalmente, e de forma relacionada, um dos projetos em andamento com Luke e Christine envolve as relações sociais de gentrificação em sua própria vizinhança no Brooklyn. Negros e brancos vivem junto, mas separados. Nós estamos interessados em trazer à superfície as sutilezas dessas formas próximas e minimalistas de existência social. Quais são as formas de intervenção que apoiam a observação etnográfica? Eu sinto que tal observação é informada por engajamentos com pessoas locais que já estão articulando insights 
"paraetnográficos" - como os populares comediantes de rua afro-americanos que ocasionalmente conseguem "bicos" em uma região de clubes racialmente divididos, como o The Ink Well. Estamos vendo modos de alinhamento com esses observadores do social em seu meio, como Douglas Holmes buscou modos de alinhamento com os banqueiros. Cada um desses projetos, embora possam abrir olhares e conceitos de "conhecimento local", é guiado por formas de repensar os métodos do etnógrafo "nativo marginal lobo solitário" que há muito me interessam. Para mim, a modalidade operante para isto é "empurrar" a etnografia como a conhecemos para entre o pensamento do design de um lado e performance e arte participativa de outro, evoluindo para novas formas de participação e conhecimento em pesquisa consistentes com os padrões de produção etnográfica do passado.

\section{Referências}

CLIFFORD, J.; MARCUS, G. E. Writing culture: the poetics and politics of ethnography. Berkeley: University of California Press, 1986.

MARCUS, G. E.; FISCHER, M. M. J. Anthropology as cultural critique: an experimental moment in the human sciences. Chicago: University of Chicago Press, 1986.

MARCUS, G. E.; HALL, P. D. Lives in trust: the fortunes of dynastic families in late twentieth-century in America. Boulder: Westview Press, 1992.

Recebido em: 28/02/2016

Aprovado em: 17/10/2016 